\title{
Relationships among Life quality, Social Support and Organizational Justice of White-collar Worker
}

\author{
Chun-mei HU ${ }^{1}$, Shu-jing CUI ${ }^{1}, \&$ Hua-min $\mathrm{HE}^{1}$ \\ ${ }^{1}$ College Education, Chongqing University of Arts and Sciences, Chongqing Yongchuan 402160, China. \\ Correspondence: Hua-min He, College Education, Chongqing University of Arts and Sciences, Chongqing Yongchuan \\ 402160, China.
}

Received: December 29, 2015

Accepted: January 12, 2016

Available online: January 20, 2016

doi:10.11114/ijsss.v4i2.1314

URL: http://dx.doi.org/10.11114/ijsss.v4i2.1314

\begin{abstract}
Objective: To explore the relationship of white-collar workers' life quality, social support and organizational justice. Methods: We used convenient sampling and questionnaire survey in the study. Totally 476 white-collar workers were from Chongqing Yongchuan by convenient sampling, they completed the whoqol-bref scale, perceived social support scale and organizational justice scale. Results: (1) The average score of white-collar workers' life quality was (87.92 \pm 10.87 ), almost $90 \%$ white-collar workers' felling of life quality and health was in the general level and above; marriage status v children status and monthly income could influence their life quality. (2)There is a significant correlation among white-collar workers' life quality, social support and organizational justice. (3) Organizational justice has partial mediating effects on the relation of social support and life quality. Conclusion: White-collar workers' life quality is in medium level, we should improve their life quality through increasing social support and organizational justice.
\end{abstract}

Keywords: white-collar worker, life quality, social support, organizational justice

\section{Introduction}

White-collar workers, one of the important human resources for China's national economic development, refers to the following people. They are civil servants of and below division level in party and government organs, administrators of and below vice-division level in state-owned enterprises, directors of and below division level in institutions, business owners of company employing 8-100 people's, managers of middle class and lower class in foreign-funded, private and three-capital enterprises, professional and technical personnel, office clerks and company employees with administrative grades (Su, 2014). However, alarmingly, with the fast social economic development, the white-collar workers suffers from increasing pressures from work and family both physically and psychologically, as it is reported in news frequently that related occupational diseases and mental illnesses has undermined their life quality. Life quality refers to individuals' experience related to the life condition, such as their goals, expectations, criteria and concerns, under different cultural circumstances and value systems. It includes individual physiological health, psychological state, independent abilities, social networks, personal beliefs and relationship with the surrounding environment (Hao \& Fang, 2000). Research on this topic mainly focused on studying people with illness, of specific occupation and old aged ( Dong et al., 2014; Yao et al., 2010; Hu et al., 2014), few study was concerning with white-collar workers. This article attempts to survey how the social support and organizational justice influence the quality of the white-collar workers' life quality, expecting to give some advice for maintaining the life quality of white-collar workers.

Social support is the system of individual person-oriented social communicating activity, it is the important reflecting of one's status in the environment(Hong, 2007). The study on social support has found the oldman's support could influence their life quality, the better social support condition could improve their life quality(Li, 2007). Social support of uremic patients, especially the friend support, could improve their life quality(Fu et al., 2006). So, we speculated white-collar workers' social support may influence their life quality.

Organizational Justice is the organizational members' subjective cognition and feelings of justice in organization, which can predict one's organizational behavior effectively(Wang \& Liao, 2007). Recent study had shown bad relationship between colleagues of white-collar workers could influence their' organizational Justice, then further influenced their subjective well-being (Wu \& Tan, 2009). Leader support of nurse had negative correlation with job burnout, and 
influenced their organizational Justice(Chen et al., 2010). The study on surgical oncology doctor indicated that their job burnout could reduce their life quality. So, we speculated social support may influence one's organizational Justice, and further influence life quality.

From the above, we hypothesised the white-collar workers' organizational Justice was mediator between life quailty and social support. In the article, we'll verify the hypothesis, then construct structural equation model among life quality, social support and organizational Justice.

\section{Participants and methods}

\subsection{Participants}

Through convenient sampling, 520 white-collar workers, from institutions and private enterprises in Yongchuan District of Chongqing in China, were chosen to be investigated by questionnaires. 476 valid questionnaires were left after elimination of invalid questionnaires and the effective rate was $91.5 \%$. Participants were classified according to gender, marriage status, with children or not, and monthly income. Among those being investigated, there were 241 male and 235 female, 247 married and 229 unmarried (including divorced), 159 with children and 317 childless, 412 with Monthly income below 5000 yuan and 64 with Monthly income of 5000 yuan and above.

\subsection{Measurement methods}

\subsubsection{World Health Organization Quality of Life Questionnaire-Brief Version, WHOQOL-BREF}

WHOQOL-BREF (Hao \& Fang, 2000) was composed of 26 items, covering four dimensions, which include physical, psychological, environmental and social relations field, as well as two independent items evaluating individual feelings about health and life quality. 1-5 points scale was used in the questionnaire, in which three questions need to score reversely. The higher total score indicated the better life quality. Cronbach's $\alpha$ of scale in this study was 0.869 .

\subsubsection{Perceived Social Support Scale, PSSS}

PSSS (Wang et al., 1999) included 12 items and three dimensions, which were family support, friend support, and other support(colleagues, leadership, etc.). 7 points score was adopted and the higher total score indicated the higher level of social support. Cronbach's $\alpha$ of scale in this study was 0.912 .

\subsubsection{Organizational Justice Survey, OJS}

OJS (Ya \& Li, 2003) included 22 items divided into four dimensions, which were procedural fair, distribution fair, leadership fair and information fair. 5 points score was adopted. The higher total score indicated the higher organizational justice experience. In this study, Cronbach's $\alpha$ of scale was 0.94 .

\subsection{Data processing}

SPSS11.5 was used to input and process data. Various methods, including independent sample t-test, product-moment correlation, intermediary test and path analysis, were adopted to analyze data.

\section{Results}

\subsection{The status quo of white-collar workers' life quality, social support and organizational justice}

The total score of white-collar workers' life quality was $87.92 \pm 10.87$. The scores of physiological, psychological, social and environmental dimensions were respectively $3.41 \pm 0.42,3.42 \pm 0.43,3.59 \pm 0.64$ and $3.25 \pm 0.55$. In the survey $52.5 \%$ white-collar workers described their life quality as "neither good nor bad", $36.6 \%$ of them described as "good" or "very good" and $10.9 \%$ of them descried as "bad" or "poor". White-collar workers describing their health as "neither good nor bad" accounted for $26.9 \%$, those describing as "good" or "very good" accounted for $61.5 \%$, and those describing as "bad" or "poor" accounted for $11.6 \%$.

The total score of white-collar workers' social support was $60.56 \pm 10.47$. The scores of family, friend and other support dimensions were respectively $5.01 \pm 1.05,5.05 \pm 0.94$ and $5.07 \pm 0.96$. The score of organizational justice was $74.52 \pm 13.67$, and the scores of process, distribution, leadership and information fairs were respectively $3.30 \pm 0.78,3.33 \pm 0.69$, $3.59 \pm 0.66$ and $3.28 \pm 0.81$.

3.2 Differences in different demographic traits of white-collar workers' life quality

An independent sample t-test was conducted on life quality of white-collar worker in different demographic traits (Table 1). 
Table1. Differences between different gender, marriage status, with children or not and monthly income $(\mathrm{M} \pm \mathrm{SD})$

\begin{tabular}{|c|c|c|c|c|c|c|}
\hline \multicolumn{2}{|c|}{ Property } & $\begin{array}{l}\text { Physical } \\
\text { dimension }\end{array}$ & $\begin{array}{l}\text { Psychological } \\
\text { dimension }\end{array}$ & $\begin{array}{c}\text { Social relations } \\
\text { dimension }\end{array}$ & $\begin{array}{c}\text { Environmental } \\
\text { dimension }\end{array}$ & Total Score \\
\hline \multirow{3}{*}{ Gender } & Male & $24.07 \pm 2.76$ & $20.52 \pm 2.75$ & $10.40 \pm 1.99$ & $26.22 \pm 4.62$ & $88.09 \pm 11.31$ \\
\hline & Female & $23.75 \pm 3.21$ & $20.60 \pm 2.41$ & $10.57 \pm 1.88$ & $25.88 \pm 4.28$ & $87.75 \pm 10.41$ \\
\hline & $t$ & 1.173 & -0.308 & -0.992 & 0.840 & 0.339 \\
\hline \multirow{3}{*}{$\begin{array}{c}\text { Marriage } \\
\text { status }\end{array}$} & Married & $24.23 \pm 2.75$ & $20.76 \pm 2.31$ & $10.59 \pm 1.85$ & $26.66 \pm 4.33$ & $89.38 \pm 10.31$ \\
\hline & Unmarried & $23.57 \pm 3.20$ & $20.35 \pm 2.84$ & $10.38 \pm 2.03$ & $25.40 \pm 4.50$ & $86.34 \pm 11.25$ \\
\hline & $T$ & $2.429 *$ & 1.743 & 1.191 & $3.129^{* *}$ & 3.070 ** \\
\hline \multirow{3}{*}{$\begin{array}{l}\text { Children } \\
\text { status }\end{array}$} & $\begin{array}{c}\text { With } \\
\text { children }\end{array}$ & $24.41 \pm 2.69$ & $20.75 \pm 2.26$ & $10.45 \pm 1.82$ & $26.73 \pm 4.48$ & $89.55 \pm 10.47$ \\
\hline & Childless & $23.67 \pm 3.10$ & $20.46 \pm 2.73$ & $10.50 \pm 1.99$ & $25.71 \pm 4.41$ & $87.10 \pm 10.99$ \\
\hline & $T$ & $2.562 *$ & 1.172 & -0.309 & $2.353 *$ & $2.335^{*}$ \\
\hline \multirow{3}{*}{$\begin{array}{c}\text { Monthly } \\
\text { income }\end{array}$} & $<5000$ & $23.72 \pm 3.01$ & $20.38 \pm 2.55$ & $10.39 \pm 1.93$ & $25.60 \pm 4.31$ & $86.92 \pm 10.58$ \\
\hline & $\geq 5000$ & $25.19 \pm 2.53$ & $21.69 \pm 2.51$ & $11.08 \pm 1.87$ & $28.98 \pm 4.26$ & $94.42 \pm 10.59$ \\
\hline & $t$ & $-3.705 * * *$ & $-3.810^{* * *}$ & $-2.648 * * *$ & $-5.852 * * *$ & $-5.282 * * *$ \\
\hline
\end{tabular}

\section{NOTE: *REFERS TO $\mathrm{P}<0.05, * *$ REFERS TO $\mathrm{P}<0.01$ ， *** REFERS TO $\mathrm{P}<0.001$ 。}

The results showed that: there was no significant difference between different genders; significant differences between the total score and the scores of physiological and environmental dimensions on the marriage status and with children or not, the married group scored higher than the unmarried, the group having children scored higher than that not having children. Significant differences existed in scores of each dimension and total score between groups with different monthly income, the group of monthly income 'of 5000 yuan and above' scored higher than that below '5000 yuan'.

\subsection{The correlation between life quality and social support, organizational justice}

Pearson product-moment correlation analysis was conducted on life quality of white-collar worker in different demographic traits(Table 2).

Table 2. Relationships between life quality, social support and organizational justice (r)

\begin{tabular}{cccccc}
\hline Property & $\begin{array}{c}\text { Physical } \\
\text { dimension }\end{array}$ & $\begin{array}{c}\text { Psychological } \\
\text { dimension }\end{array}$ & $\begin{array}{c}\text { Social } \\
\text { relations } \\
\text { dimension }\end{array}$ & $\begin{array}{c}\text { Environmental } \\
\text { dimension }\end{array}$ & $\begin{array}{c}\text { Total Score of } \\
\text { life quality }\end{array}$ \\
\hline Family support & $0.378^{* *}$ & $0.324^{* *}$ & $0.494^{* *}$ & $0.403^{* * *}$ & $0.485^{* *}$ \\
$\begin{array}{c}\text { Friend support } \\
\text { Other support }\end{array}$ & $0.314^{* *}$ & $0.337^{* *}$ & $0.576^{* *}$ & $0.444^{* *}$ & $0.498^{* *}$ \\
$\begin{array}{c}\text { Total Score of } \\
\text { support }\end{array}$ & $0.391^{* *}$ & $0.350^{* *}$ & $0.553^{* *}$ & $0.467^{* *}$ & $0.530^{* *}$ \\
Procedural fair & $0.499^{* *}$ & $0.381^{* *}$ & $0.610^{* *}$ & $0.495^{* *}$ & $0.570^{* *}$ \\
Distribution fair & $0.370^{* *}$ & $0.305^{* *}$ & $0.335^{* *}$ & $0.450^{* * *}$ & $0.474^{* *}$ \\
Leadership fair & $0.493^{* *}$ & $0.469^{* *}$ & $0.447^{* *}$ & $0.539^{* *}$ & $0.611^{* *}$ \\
Information fair & $0.463^{* *}$ & $0.381^{* *}$ & $0.430^{* *}$ & $0.503^{* *}$ & $0.558^{* *}$ \\
Total Score of justice & $0.540^{* *}$ & $0.468^{* *}$ & $0.495^{* *}$ & $0.599^{* *}$ & $0.664^{* *}$ \\
\hline
\end{tabular}

NOTE: *REFERS TO $P<0.05, * *$ REFERS TO $P<0.01, * * *$ REFERS TO $P<0.001$ 。

The results indicated the following: the total score of life quality and scores of each dimension were all correlated positively and significantly with social support total score and scores of each dimension. Also, the total score of life quality and scores of each dimension were all correlated positively and significantly with organizational justice experience total score and scores of each dimension. Therefore, the prerequisite of the intermediary test was satisfied. 
3.4 The intermediary test for organizational justice between life quality and social support

The intermediary test was conducted to verify whether organizational Justice was mediator between life quailty and social support. The test was based on the definition of mediate variables and inspection procedures of intermediary test proposed by Zhonglin Wen (Wen et al., 2004). All variables were centralized before intermediary test (Table 3).

Table 3. Intermediary test for organizational justice to life quality

\begin{tabular}{cccc}
\hline Steps & Standardized regression equation & $S E$ & $t$ \\
\hline Step one & $\mathrm{Y}=0.57 \mathrm{x}$ & 0.039 & $15.102^{* * *}$ \\
Step two & $\mathrm{M}=0.508 \mathrm{x}$ & 0.052 & $12.856^{* * *}$ \\
Step three & $\mathrm{Y}=0.313 \mathrm{x}+0.505 \mathrm{M}$ & 0.030 & $13.573^{* * *}$ \\
\hline
\end{tabular}

\section{NOTE: SE REFERS TO Standard Error}

Firstly, regression analysis was conducted to inspect the direct impact of social support on life quality, with life quality as dependent variable (y) and social support as independent variable (x). Secondly, regression analysis was conducted to inspect the direct impact of social support on organizational justice, with organizational justice as dependent variable (y) and social support as independent variable (x). Thirdly, regression analysis was conducted to inspect whether the organizational justice had an intermediary effect on the relation between social support and life quality, with life quality as dependent variable (y) and social support, organizational justice as independent variables (x).

After considering the intermediary effect of organizational justice, the prediction coefficient of social support on life quality, though still significant statistically $(\mathrm{P}<0.001)$, however, dramatically reduced from 0.570 to 0.313 . The proportion of the mediation effect to total effect was $45 \%$. The result indicated that organizational justice had partial intermediary effect on the relation between social support and life quality. This proved the hypothesis.

\subsection{The structural equation modeling among life quality, social support and organizational justice}

According to the result of the intermediary test, we constructed the model on the relationship among life quality, social support and organizational justice (Figure 1). We used Amos5.0 to verify the models' applicableness.

Table 4. Goodness-of-fit index of the model

\begin{tabular}{lllllllll}
\hline$\chi^{2} / \mathrm{df}$ & RMSEA & GFI & CFI & AGFI & TLI & RFI & IFI & NFI \\
\hline 2.99 & 0.076 & 0.945 & 0.961 & 0.912 & 0.948 & 0.930 & 0.961 & 0.948 \\
\hline
\end{tabular}

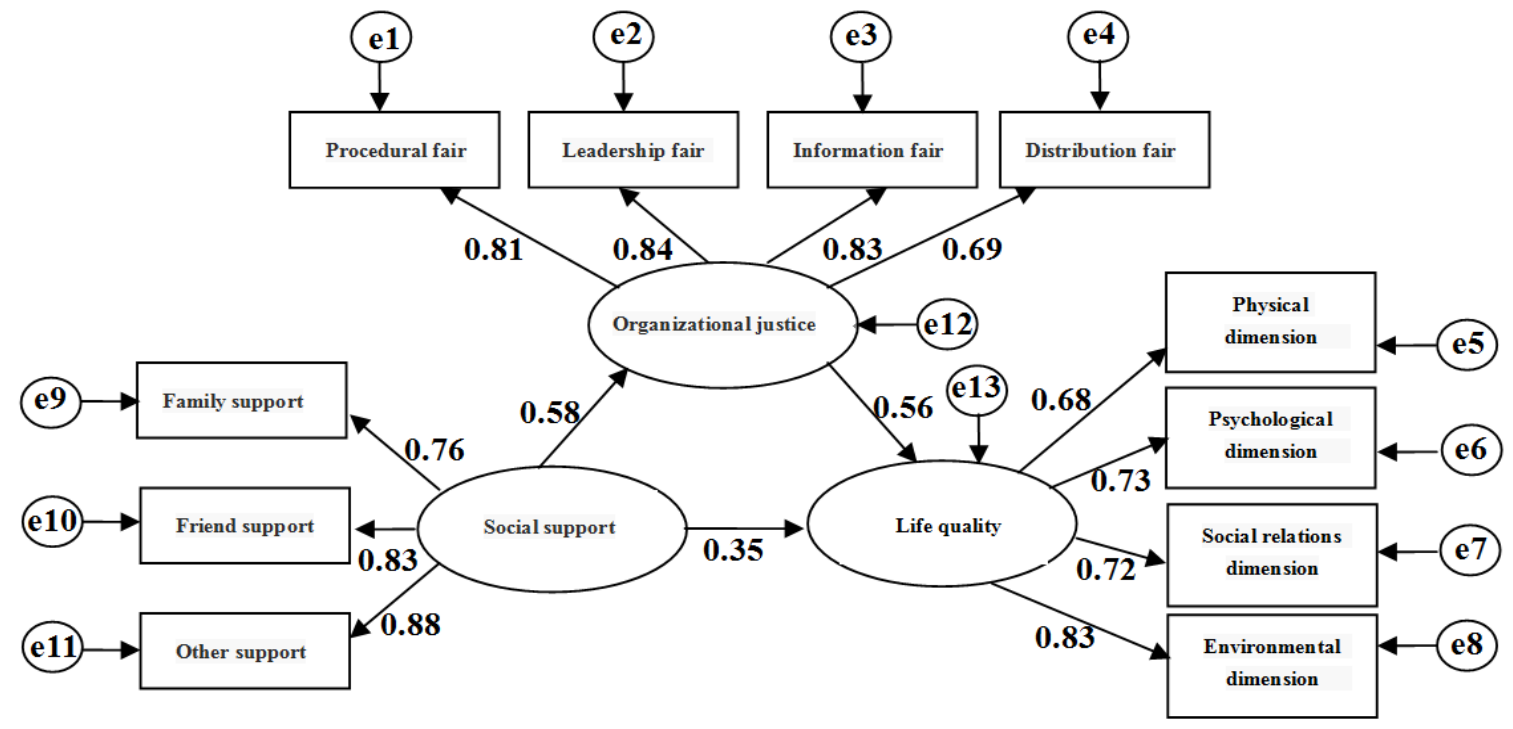

Figure1. The structural equation modeling among life quality, social support and organizational justice

The results showed that the goodness-of-fit index of the model were all fitting standards: $2<\chi^{2} / \mathrm{df}<3$, RMSEA $<0.08$, GFI, CFI, AGFI, TLI, RFI, IFI, NFI were all $>0.9$ (Table 4), indicating that the model was fitting good (Wu \& Tu, 2012). 
The significance levels of the path, which the social support impacted life quality, social support impacted organizational justice and organizational justice impacted life quality, were respectively $0.35 *, 0.58 *, 0.56 *(\mathrm{P}<0.01)$. The structural equation model proved that social support of white-collar workers not only affected the life quality directly, but also affected the life quality indirectly through the intermediary effect of organizational justice experience.

\section{Discussion}

The research found that white-collar workers' life quality scored averagely above 80 and nearly $90 \%$ of white-collar workers described their life quality as "neither good nor bad, good or very good", showing that their life quality were in medium level. Besides, it was also found that the married group scored better than the unmarried, the group with children scored better than the childless group, the higher monthly income group scored better than the lower monthly income group. That was consistent with the results of previous research(Hu et al., 2014; Xu et al., 2014). Marriage can improve social relations of individuals and satisfaction of social support, so married white-collar workers felt happier. White-collar workers having children could experience a feeling of life continuation and fulfillment through the interaction with children and creation of harmonious family relations while raising and educating children, so they were more satisfied with their life quality. High income mighty easily endow people a sense of control and satisfy their material and spiritual desires, so white-collar workers with a higher income experienced better life quality.

The research results indicated that higher organizational justice score of white-collar workers was associated with better life quality and higher social support with better life quality. That was consistent with the results of previous research (Yao et al., 2010; Xie et al., 2008). The intermediary test found that social support would not only directly affect life quality, but also affect life quality through organizational justice indirectly. It indicated that white-collar workers with more social support had better life quality, meanwhile, they experienced a better feeling of organizational justice, which further improved their life quality. Social support affected ones' subjective well-being (Yan \& Zheng, 2008) and psychological health (Wang \& Shi, 2008), further directly affected white-collar workers' life quality (Wu \& Tan, 2009). At the same time, support from colleagues and leaders at work affected white-collar workers' organizational justice. Apart from that, family support might improve their job involvement and work efficiency as well as satisfaction to the organization, reduced their job burnout, thus improved their life quality.

To sum up, we suggest that life quality of white-collar workers should be improved through improving their social support and organizational justice. On one hand, the directors of workplaces should pay attention to coordinate the relationships and enhance communications among employees so as to build harmonious working atmosphere, so the colleagues can support each other. Managers in enterprises should also give leadership support and show more concerns for the staff. On the other hand, enterprises should develop fair systems of salary and making policies by considering fairness among employees in order to improve the white-collar workers' organizational justice and satisfaction with enterprise, then promote their psychological well-being, and further improve their life quality.

\section{Limitation and future research}

As convenient sampling was used to select the participants in this research, the range of samples was limited and failed to cover the whole white-collar workers' group. That made the research results not representative enough to a certain extent. In the follow-up studies, we will improve the research methods, enlarge the sample size and scope so as to acquire results more representative.

\section{References}

Chen, C. R., Chen, Y. C., Yang, Y. Q., \& Duan, G. X. (2010). Path analysis of the influencing factors of nurses' organizational justice. Chin J Nurs, 45(10), 877-880.

Dong, S. L., Wang, F. W., Xin, F. M. (2014). Effects of self-efficacy intervention on the life quality of patients with chronic obstructive pulmonary disease. Modern preventive medicine, 41(18), 3357-2259.

Fu, F. Q., Wang, Z. W., \& Wan, Q. Q. (2006). The influence of social support and coping style on maintenance hemodialysis' life quality. Chinese Journal of Nursing, 41(2), 130-132.

Hao, Y. T., \& Fang, J. Q. (2000). The introduction and usage of WHOQOL in Chinese[J]. Modern Rehabilitation, 4(8), 1127-1129.

Hong, D. M. (2007). Influence of Social Support and Psychological Control Sense on Sense of Adequacy of Undergraduates. Chinese Journal of Clinical Psychology, 15(6), 627- 628.

$\mathrm{Hu}$,L. R., Ning, W. H., \& Wu, J. Y., et al. (2014). Analysis on present situation of life quality and influence factors of 418 elderly residents in Zhanjiang city. Chongqing Medicine, 43(12), 1488-1490.

Li, J. X. (2007). Social Support and Quality of Life of the Elderly in China. Population Research, 31(3), 50-59. 
Liu, Y., Long, L. R., \& Li, Y. (2003). Research on the effect of organizational justice on justice dimensions on key outcomes. Management World, 3, 126-132.

$\mathrm{Su}$, Y. Y. (2014). Research into Consumption ideology and behavior of white-collar youth in urban area. China youth study, 4, 49-60.

Wang, L. F., \& Shi, Y. J. (2008). Social support and mental health of the empty-nest elderly people in urban area. Chinese mental health journal, 22(2), 118-122.

Wang, X. D., Wang, X. L., \& Ma, H., et al. (1999). Handbook of Rating Scales for Mental Health (Revised). Chinese mental health journal, 12, 330-332.

Wen, Z. L., Zhang, L., \& Hou, J. T., et al. (2004). Testing and application of the mediating effects. Acta Psychologica Sinica, 36(5), 614-620.

Wu, L. P., \& Tan, J. (2009). Research into the effect of white-collar youth's social relationship on subjective well-being: an analysis on interview in-depth for 8 white-collar workers in IT industry in Beijing. China youth study, 7, 55-58.

Wu, M. L., \& Tu, J. T. (2012). SPSS \& the Application and Analysis of Statics. Dongbei University of Finance \& Economics Press, 9, 476-749.

Xie, W. S., \& Ruan, Y. (2008). A survey and assessment of college students' quality of life in Anhui. China Journal of Health psychology, 16(10), 1123-1124.

Xu, X. J., Wang, X. J., \& Ni, J. D. (2014). Factors affecting quality of life among employees of public institutions:a structural equation model. China public health, 30(3), 346-349.

Wang, X. Y., \& Liao, J. Q. (2007). Study on the influencing mechanism between organizational Justice and job performance of staff. Jiangxi Social Sciences, 9, 152-156.

Yan, B. B., \& Zheng, X. (2006). Research into relations among social support, self-esteem and subjective well-being of college students. Psychological development and education, 3, 60-64.

Yao, S. M., Li, W., \& Song, P. P. (2010). The study of quality of life and related factors among medical college teacher. Modern preventive medicine, 37(1), 69-72.

\section{(c) EY EY}

This work is licensed under a Creative Commons Attribution 3.0 License. 